\title{
Effect of Lactoperoxidase and Thiocyanate on the Growth of Streptococcus pyogenes and Streptococcus agalactiae in a Chemically Defined Culture Medium
}

\author{
By M. N. MICKELSON \\ Animal Disease and Parasite Research Division, Agricultural \\ Research Service, U.S. Department of Agriculture, National Animal \\ Disease Laboratory, Ames, Iowa, U.S.A.
}

(Received 10 August 1965)

\begin{abstract}
SUMMARY
A chemically defined culture medium was used to study the effect of purified lactoperoxidase and thiocyanate on the growth of several cultures of Streptococcus pyogenes and S. agalactiae. While not inhibited by either component alone, $S$. pyogenes growth was completely inhibited when both components were present in the medium. The growth inhibition was annulled completely by glutathione, thioglycollic (mercaptoacetic) acid or catalase. S. pyogenes glyceraldehyde phosphate dehydrogenase was inhibited by lactoperoxidase when hydrogen peroxide was present. The inhibition was annulled with cysteine and glutathione which suggested this dehydrogenase to be a possible site of inhibition. The inhibition was postulated to be a peroxidatic conversion of essential enzymic sulphydryl groups to inactive disulphide groups, thus interfering with the energy metabolism of $\boldsymbol{S}$. pyogenes. With $\boldsymbol{S}$. agalactiae cultures a delay in growth inhibition up to $6 \mathrm{hr}$ resulted instead of complete growth inhibition. Catalase neutralized this effect. The extent of growth inhibition was greatest in those strains which were unable to adapt to an oxidative pathway for their energy supply. In becoming independent of the fermentative pathway, the cultures were no longer as sensitive to peroxidase, thiocyanate and hydrogen peroxide. The necessity for thiocyanate in the inhibitory system is not yet clear. Thiouracil and thiourea were ineffective replacements for thiocyanate.
\end{abstract}

\section{INTRODUCTION}

Streptococcus pyogenes (Lancefield, group $\mathbf{A}$ ) and $\boldsymbol{S}$. agalactiae (Lancefield, group B) have been used to study the naturally occurring bacterial growth inhibitors in milk (Auclair \& Hirsch, 1953; Jones \& Simms, 1930; Wilson \& Rosemblum, 1952). Streptococcus pyogenes is a human pathogen which rarely infects the bovine udder, whereas $S$. agalactiae is one of the principal causes of bovine streptococcal mastitis. These organisms differ in their sensitivity to the natural inhibitors in milk and in their nutritional requirements. They are similar in morphology and under anaerobic conditions both are homofermentative lactic acid bacteria. Jones \& Simms (1930) showed that $S$. pyogenes decreased in numbers when inoculated into raw milk, whereas $S$. agalactiae grew rapidly after a lag period of $6-8 \mathrm{hr}$. This was explained as an adaptation to the inhibitory factor during the lag phase.

Wright \& Tramer (1958), using Streptococcus cremoris 972, and Portmann \& 
Auclair (1959), using $S$. cremoris 972 and $S$. pyogenes Richards, established lactoperoxidase as a component of the natural inhibitor complex in milk. The inhibitory action of lactoperoxidase for $S$. cremoris 972 has been confirmed in a whey ultrafiltrate medium supplemented with an amino acid mixture (Jago \& Morrison, 1962). Reiter, Pickering \& Oram (1964) showed that, in addition to lactoperoxidase and hydrogen peroxide, a thermostable, dialysable, acid-resistant substance present in milk was necessary for inhibition of lactoperoxidase-sensitive organisms. The latter substance was identified as thiocyanate.

The present report deals with the response of several strains of Streptococcus pyogenes and $S$. agalactiae to purified lactoperoxidase and thiocyanate in a chemically defined medium. Some preliminary studies on metabolic differences between $S$. pyogenes and $S$. agalactiae strains have been used to explain the difference in growth inhibition that was observed.

\section{METHODS}

Cultures. Seven cultures of Streptococcus pyogenes were used. All were obtained from Dr H. D. Slade, Department of Microbiology, Northwestern University Medical School, Chicago, Illinois. They represented the following serotypes: $3 S$. pyogenes Richards, 19 S. pyogenes $\times 19,6$ S. pyogenes $\mathrm{s} 43,1,5,25$ and 30 . Six strains of $S$. agalactiae $660-1,50,80,142,356,383$ were from our collection, and a seventh strain, Cornell 48, was obtained from Dr G. E. Morse, School of Veterinary Medicine, University of Pennsylvania, Philadelphia, Pennsylvania.

Lactoperoxidase preparation and assay. Lactoperoxidase (LPO) was prepared from fresh skimmed milk by the procedure of Morrison \& Hultquist (1963). The purified enzyme was stored at $4^{\circ}$ with toluene in the $0.5 \mathrm{M}$-sodium acetate solution used to elute the enzyme from the second resin column. The enzyme solution had a 412/280 $\mathrm{m} \mu$ absorption ratio of 0.93 . By assay, it contained 14.5 units lactoperoxidase $/ \mathrm{ml}$. and the activity changed very little during 3 months' storage.

Peroxidase activity was measured by a pyrogallol method. The reagents used were: $0.2 \mathrm{M}$-phosphate buffer ( $\mathrm{pH} \mathrm{6.9}$ ), freshly prepared $0.05 \mathrm{~m}$-hydrogen peroxide, freshly prepared $1 \%$ aqueous pyrogallol, and a peroxidase standard containing $5 \mathrm{mg}$. horseradish peroxidase (Nutritional Biochemicals Corp., Cleveland, Ohio, 100 units/mg.)/100 ml. 0.01 $\mathrm{m}$-phosphate buffer $(\mathrm{pH} \mathrm{7.0)}$. This stock solution was diluted $1 / 10$ just before use in preparing a standard peroxidase activity curve with $0.01,0.03$ and 0.05 units. A standard curve was run with each assay.

The assay was performed by adding the reagents and sample to a Klett-Summerson colorimeter tube in the following order: $4.0 \mathrm{ml}$. buffer, sample, distilled water to $5.2 \mathrm{ml}$., $0.15 \mathrm{ml}$. hydrogen peroxide solution, and $0.15 \mathrm{ml}$. pyrogallol solution. The contents of the tube were mixed, held for $10 \mathrm{~min}$. at room temperature, then $0.5 \mathrm{ml}$. $4 \mathrm{~N}-\mathrm{H}_{2} \mathrm{SO}_{4}$ was added and the colour was measured with a KlettSummerson colorimeter with a no. 42 filter.

The peroxidase activities of the lactoperoxidase preparation and whey samples were expressed in terms of horseradish peroxidase units. Whey samples from fresh milk contained 0.60-0.75 unit $/ \mathrm{ml}$.

Growth inhibition tests. The tests were carried out in a chemically defined medium (Mickelson, 1964), which was sterilized at $100^{\circ}$ (steaming for $15 \mathrm{~min}$.). Glutathione 
(GSH), thioglycollic (mercaptoacetic) acid, catalase and ammonium thiocyanate $\left(\mathrm{SCN}^{-}\right)$solutions were sterilized by filtration through an ultrafine sintered glass filter before adding to the medium. Lactoperoxidase was heated for $30 \mathrm{~min}$. at $60^{\circ}$ in a water bath, just before use, to expel toluene. Tests were done in a total volume of $4 \mathrm{ml}$. of medium including the added compounds in $13 \times 100 \mathrm{~mm}$. screw-capped tubes. Each tube was inoculated with a 16-18 hr culture of Streptococcus pyogenes or $S$. agalactiae grown in the chemically defined medium. The inoculum, 1-2\% by volume of the test medium, was added so that the extinction reading of the inoculated medium was $0 \cdot 05-0 \cdot 08$. After incubation at $37^{\circ}$ measurements of growth were made in a Bausch \& Lomb Spectronic 20 colorimeter at $550 \mathrm{~m} \mu$.

Manometric studies. Streptococcus pyogenes was grown in Brain Heart Infusion broth (Baltimore Biological Laboratories, Baltimore, Md., U.S.A.), which was supplemented with glucose to $0.8 \%$ concentration and $0.1 \mathrm{M}$-phosphate buffer $(\mathrm{pH} \mathrm{7 \cdot 0).} \mathrm{S.} \mathrm{agalactiae} \mathrm{was} \mathrm{grown} \mathrm{in} \mathrm{a} \mathrm{medium} \mathrm{containing} 1 \%$ yeast extract (Difco, Detroit, Michigan), 0.4\% Casitone (Difco), 0.8\% glucose and 0.1 M-phosphate $(\mathrm{pH} \mathrm{7 \cdot 0)}$. The phosphate buffer (M) was sterilized and added separately. Stationary and shaken cultures were grown in $50 \mathrm{ml}$. of medium in $125 \mathrm{ml}$. screw-capped Erlenmeyer flasks. The shaker cultures were grown in loosely capped flasks on a rotary shaker (New Brunswick Gyrotary Shaker Model s-3) at 120 rev./min. After incubation at $37^{\circ}$ for $16 \mathrm{hr}$ the cocci were harvested by centrifugation, washed once with distilled water, and resuspended to a concentration equiv. 10-12 mg. dry wt. cocci/ml. Four to five mg. cocci were used per respirometer flask in $2 \mathrm{ml}$. reactants. Respiratory activity was measured by conventional Warburg manometric procedure at $37^{\circ}$. When cyanide was used in the main flask compartment, $\mathrm{M}-\mathrm{KCN}$ was substituted for $0.3 \mathrm{~N}$-potassium hydroxide in the centre well.

Cell-free extracts of Streptococcus pyogenes s43, type 6 for measurement of triosephosphate dehydrogenase were prepared from cocci grown in stationary culture for 12-14 hr in supplemented brain heart infusion broth. The cocci were harvested by centrifugation, washed once with $0.02 \mathrm{M}-\mathrm{NaHCO}_{3}$, and the paste was mixed with an equal weight of alumina (No. A-305, Alcoa Chemicals, Aluminum Company of America, 1205 Alcoa Bldg., Pittsburgh, Pa.). The mixture was frozen in the deep freeze on a piece of glassine paper, then ground in a chilled mortar for $5 \mathrm{~min}$. The ground paste was transferred from the mortar to a plastic centrifuge tube by slow successive additions of $1 \mathrm{ml}$. 0.075 M-phosphate buffer ( $\mathrm{pH} \mathrm{7.5}$ ), for each 50-60 mg. dry wt. cocci. The cell debris and alumina were removed by centrifugation at $3000 \mathrm{~g}$ for $10 \mathrm{~min}$. and the supernatant fluid was centrifuged at $20,000 \mathrm{~g}$ for $20 \mathrm{~min}$. The enzymic activity was present in the supernatant fluid which was either held at $4^{\circ}$ when assayed on the same day as preparation or at $-70^{\circ}$ when held for several days. The protein content of the bacterial extracts was determined by a method described by Stadtman, Novelli \& Lipmann (1951).

Peroxidase activity was determined by titration of the residual hydrogen peroxide after shaking coccal suspensions in Warburg flasks for 60 min. at $37^{\circ}$ with $0.2 \mathrm{ml}$. $0.05 \mathrm{M}$-hydrogen peroxide in the presence and absence of $0.02 \mathrm{M}$-glucose. After adding $0 \cdot 2 \mathrm{ml} .4 \mathrm{~N}_{2}-\mathrm{H}_{2} \mathrm{SO}_{4}$ from a side arm at the end of the experiment to stop the reaction, the contents of each flask were transferred with washings into a centrifuge tube in a volume of about $8 \mathrm{ml}$. After centrifuging, each supernatant fluid was transferred to a $18 \times 125 \mathrm{~mm}$. tube, $0.5 \mathrm{ml}$. of $10 \% \mathrm{KI}$ and 1 drop of $1 \%$ ammonium 
molybdate were added and the iodine was titrated with $0.005 \mathrm{~N}-\mathrm{Na}_{2} \mathrm{~S}_{2} \mathrm{O}_{3}$. Control flasks consisted of peroxide alone, peroxide+glucose, and peroxide + glucose acidified with $0.2 \mathrm{ml} .4 \mathrm{~N}-\mathrm{H}_{2} \mathrm{SO}_{4}$ before adding cocci.

Lactic dehydrogenase (rabbit muscle, 2x, Nutritional Biochemicals Corp.) activity was measured by a decrease in absorption at $340 \mathrm{~m} \mu$ due to oxidation of reduced diphosphopyridine nucleotide (NADH) with pyruvate as the substrate. Glyceraldehydephosphate dehydrogenase activity in cell-free extracts of Streptococcus pyogenes was measured by an increase in absorption at $340 \mathrm{~m} \mu$ with glyceraldehyde3-phosphate as the substrate. When purified rabbit muscle dehydrogenase (rabbit muscle, Calbiochem, A grade) was studied D-glyceraldehyde was the substrate (Colowick \& Kaplan, 1959). Absorption measurements at $340 \mathrm{~m} \mu$ were made with a Beckman DU-2 spectrophotometer. The enzymes were incubated at room temperature for $30 \mathrm{~min}$. with the components of the inhibitory complex, singly and in admixture, before addition of substrate. Diphosphopyridinenucleotides, glyceraldehyde-3-phosphate, $D$-glyceraldehyde and catalase were obtained from Nutritional Biochemicals Corp., Cleveland, Ohio. The catalase was diluted to contain 5 units $/ \mathrm{ml}$. and sterilized by filtration before addition to culture media.

Flavinadeninedinucleotide $(F A D)$ was determined in bacterial extracts by the enzymic method of DeLuca, Weber, \& Kaplan (1956). Total flavin was measured on extracts of the cocci by absorption at $445 \mathrm{~m} \mu$. Extracts were prepared by suspending $0.10 \mathrm{~g}$. lyophilized cocci in $10 \mathrm{ml}$. 0.01 $\mathrm{M}$-phosphate buffer ( $\mathrm{pH} \mathrm{7.5)}$ and heating in a boiling water bath for $10 \mathrm{~min}$. After cooling, the extract was centrifuged for $20 \mathrm{~min}$. at $20,000 \mathrm{~g}$ to obtain a clear supernatant fluid. The extraction procedure was repeated with $3 \mathrm{ml}$. of the buffer and the supernatant fluids were pooled for analysis. Flavinadeninedinucleotide as $\%$ of total flavin was calculated according to DeLuca et al. (1956).

Glucose and lactic acid were determined by the anthrone procedure and the Barker \& Summerson procedure, respectively, as described by Umbreit, Burris \& Stauffer (1957). The contents of the Warburg vessels were transferred with washings into a graduated centrifuge tube. One $\mathrm{ml}$. of $5 \% \mathrm{ZnSO}_{4} .7 \mathrm{H}_{2} \mathrm{O}$ and $1 \mathrm{ml}$. of $0.3 \mathrm{~N}-\mathrm{Ba}(\mathrm{OH})_{2}$ were added and the volume was made up to $10 \mathrm{ml}$. The contents of the tube were centrifuged and analyses done on the clarified supernatant liquid.

\section{RESULTS}

Table 1 shows data comparing the effect of lactoperoxidase, thiocyanate and combinations of the two on the growth of five strains of Streptococcus pyogenes in the chemically defined medium. The lactoperoxidase and thiocyanate concentrations were in the range of those normally found in milk. Complete growth inhibition occurred with all strains tested in the presence of lactoperoxidase and thiocyanate. Either component alone had no effect on growth.

The growth inhibition of Streptococcus pyogenes $\mathrm{N} 19$, as influenced by various concentrations of thiocyanate in the presence of 0.5 unit lactoperoxidase $/ \mathrm{ml}$., is shown in Fig. 1. At this concentration of lactoperoxidase, $2 \mu \mathrm{g}$. ammonium thiocyanate/ml. stopped growth for $24 \mathrm{hr}$. No growth occurred on continued incubation. The other four strains of $S$. pyogenes were also inhibited by these concentrations of lactoperoxidase and thiocyanate. Growth inhibition could be annulled completely 
Table 1. The effect of lactoperoxidase, ammonium thiocyanate singly and in admixture on the growth of five serotypes of Streptococcus pyogenes in a chemically defined medium

\section{Additions to medium}

None

LPO 0.6 unit $/ \mathrm{ml}$.

NH, SCN $15 \mu \mathrm{g} \cdot / \mathrm{ml}$.

LPO 0.6 unit/ml., $\mathrm{NH}_{4} \mathrm{SCN} 5 \mu \mathrm{g} . / \mathrm{ml}$.

\begin{tabular}{ccccc}
\multicolumn{5}{c}{ Growth of serotype* } \\
\hline 19 & 1 & 5 & 25 & 30 \\
0.70 & 0.60 & 0.64 & 0.79 & 0.69 \\
0.65 & 0.57 & 0.67 & 0.80 & 0.66 \\
0.66 & 0.68 & 0.66 & 0.77 & 0.75 \\
0.07 & 0.08 & 0.08 & 0.08 & 0.08
\end{tabular}

* Growth measured as extinction at $500 \mathrm{~m} \mu$ after $24 \mathrm{hr}$ in $13 \times 100 \mathrm{ml}$. culture tubes.

$\uparrow \mathbf{L P O}=$ lactoperoxidase.

by addition of $0.05 \mathrm{M}$-glutathione, $0.005 \mathrm{M}$-thioglycollic (mercaptoacetic) acid, or 0.1 unit catalase/ml. (Fig. 2). Lactoperoxidase ( $0.7 \mathrm{unit} / \mathrm{ml}$.) was not active with thiouracil or thiourea (15 and $30 \mu \mathrm{g}$. $/ \mathrm{ml}$.) when substituted for thiocyanate in growth inhibition tests with $S$. pyogenes N 19.

The sensitivity of Streptococcus agalactiae cultures to lactoperoxidase, thiocyanate or their combination was tested under conditions similar to those used for $S$. pyogenes. The $S$. agalactiae strains grew more rapidly than $S$. pyogenes strains and extinctions as high as 1.00 were sometimes obtained in the control tubes after $12 \mathrm{hr}$ incubation. Complete growth inhibition was not obtained with any of the seven cultures tested. The growth inhibitory effect for $S$. agalactiae ranged from none with strain 50 to a maximum delay in growth initiation of $6 \mathrm{hr}$ beyond that of

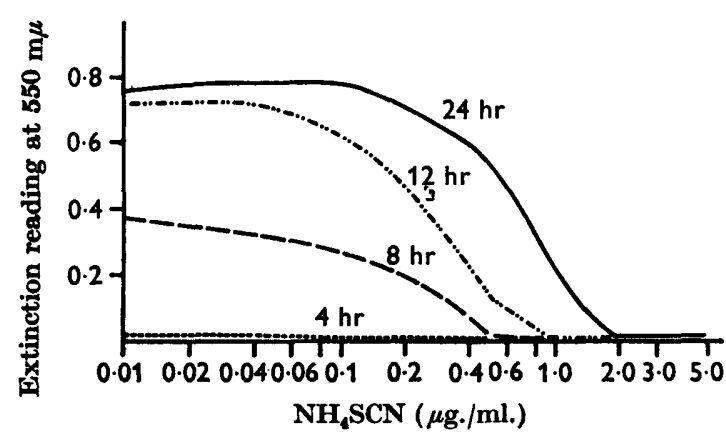

Fig. 1

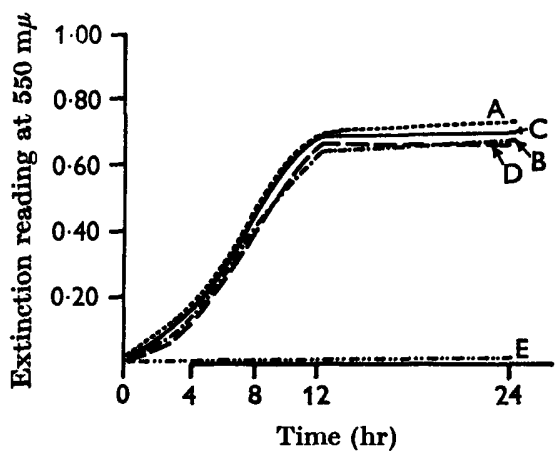

Fig. 2

Fig. 1. Influence of thiocyanate concentration in the presence of lactoperoxidase (0.5 unit/ml.) on the growth of Streptococcus pyogenes $\mathrm{N} 19$ in a chemically defined medium.

Fig. 2. Growth inhibition of Streptococcus pyogenes $N 19$ in a chemically defined medium by lactoperoxidase and thiocyanate and its reversibility with glutathione, thioglycollic acid and catalase. Curve $C=$ control; curve $E=L P O, 0.5$ unit $/ \mathrm{ml}$, + ammonium thiocyanate, $2 \mu \mathrm{g} . / \mathrm{ml}$.; curve $B=$ same as $(E)+$ catalase $0 \cdot 1$ unit $/ \mathrm{ml}$.; curve $D=$ same as (E) plus 0.005 M-GSH; curve $A=$ same as (E) + 0.005 M-sodium thioglycollate.

the control with strain 80, Fig. 8. Varying the thiocyanate concentration from 5 to $45 \mu \mathrm{g} . / \mathrm{ml}$. medium with a lactoperoxidase concentration of $0.6 \mathrm{unit} / \mathrm{ml}$. had no effect on growth.

To determine whether the delay in growth initiation observed with certain 
cultures of Streptococcus agalactiae was related to hydrogen peroxide formation, catalase was added to the chemically defined medium in the presence and absence of lactoperoxidase and thiocyanate. The addition of catalase ( $0.1 \mathrm{unit} / \mathrm{ml}$.) not only abolished the delay in growth caused by the inhibitor complex but also caused a more rapid growth rate than in the controls which contained no lactoperoxidase or thiocyanate.

The decomposition of hydrogen peroxide by suspensions of Streptococcus agalactiae 50 grown on the shaker is shown in Table 2. The dry weights of cocci per flask

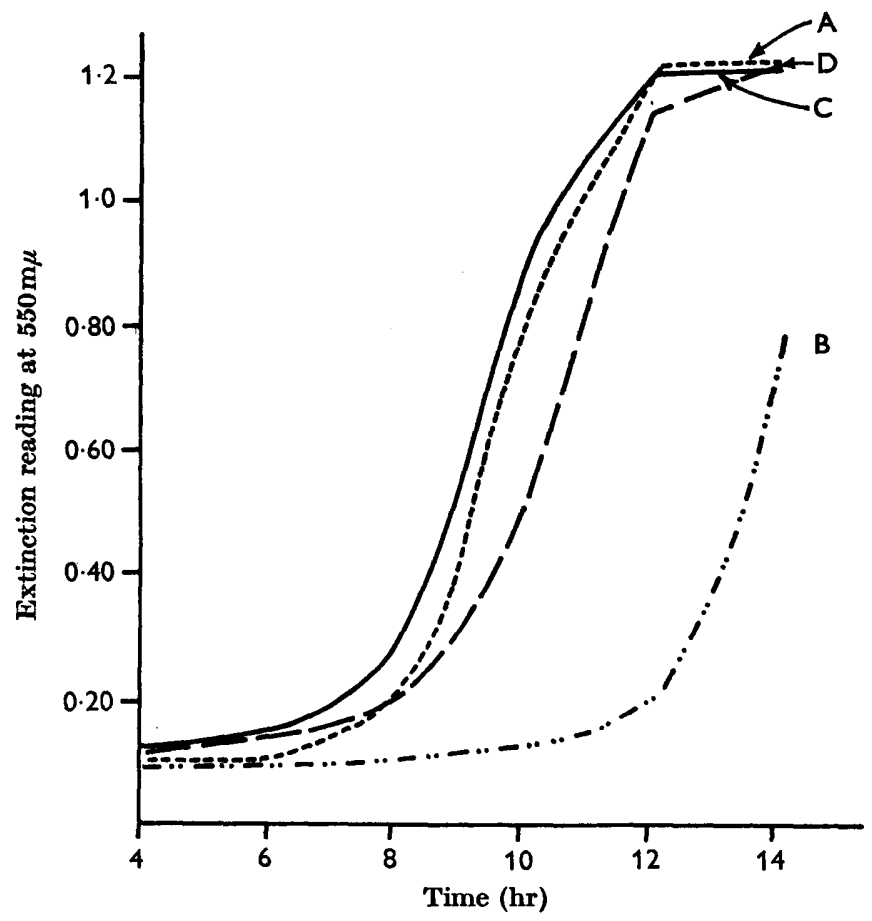

Fig. 3. Effect of lactoperoxidase, thiocyanate and their combination on the growth of Streptococcus agalactiae 80 in a chemically defined medium. Curve $\mathrm{C}=$ control; curve $A=$ ammonium thiocyanate $15 \mu \mathrm{g} . / \mathrm{ml}$.; curve $D=L P O ~ 0.75 ~ u n i t / m l$. ; curve B = LPO, 0.75 unit/ml., + ammonium thiocyanate $15 \mu \mathrm{g} . / \mathrm{ml}$.

were 20, 7·3, 6.6, 6 and 8.5 mg., respectively, for Expts. 1-5. There was no catalase activity that could be measured manometrically. $S$. agalactiae continued to respire in the presence of the hydrogen peroxide at $40 \%$ of the rate in the absence of peroxide. Correction was made for the oxygen produced from the decomposition of peroxide. The amount of hydrogen peroxide which disappeared during endogenous respiration was one-half to one-third that in the presence of glucose. With longer incubation and more respiration, there was more peroxide disappearance.

The second part of Table 2 shows results from two experiments with each of three cultures of Streptococcus pyogenes. Seven to $14 \mathrm{mg}$. dry cocci were used per flask. The respiration rate in the presence of peroxide with $S$. pyogenes $\mathrm{s} 43$ was only $10-15 \%$ of that when peroxide was not present. Hydrogen peroxide disappeared 
from the reaction mixture when glucose was present and a small amount during the endogenous respiration. $S$. pyogenes Richards destroyed or utilized 85-100\% of the hydrogen peroxide added. In Expt. 1 with $S$. pyogenes $\mathrm{s} 43$, the destruction of peroxide was by catalase action. From $9 \cdot 1 \mu$ mole hydrogen peroxide $4 \cdot 1 \mu$ mole oxygen were evolved when cocci were added to hydrogen peroxide in the absence of glucose.

Table 2. Hydrogen peroxide decomposition by suspensions of Streptococcus agalactiae 50 and Streptococcus pyogenes cultures

$\mu \mathrm{mole} \mathrm{H}_{2} \mathrm{O}_{2}$ decomposed/mg. dry-wt. cocci/hr

\begin{tabular}{|c|c|c|c|c|c|c|}
\hline \multicolumn{7}{|c|}{ S. agalactiae $\mathbf{5 0}$} \\
\hline Expt. no. & 1 & \multicolumn{2}{|c|}{2} & & 4 & $\mathbf{5}$ \\
\hline $\begin{array}{l}\mathrm{H}_{2} \mathrm{O}_{2}+\text { cocei } \\
\mathrm{H}_{2} \mathrm{O}_{2}+\text { glucose }+ \text { cocei } \\
{ }^{*} \mathrm{H}_{2} \mathrm{O}_{2}+\text { glucose }+ \text { cocci }\end{array}$ & $\begin{array}{l}0 \cdot 15 \\
0 \cdot 28 \\
0 \cdot 037\end{array}$ & & & $\begin{array}{l}89 \\
053\end{array}$ & $\begin{array}{l}0 \cdot 60 \\
0 \cdot 87 \\
0 \cdot 08\end{array}$ & $\begin{array}{l}0 \cdot 11 \\
0 \cdot 29 \\
0 \cdot 034\end{array}$ \\
\hline \multicolumn{7}{|c|}{ S. pyogenes culture } \\
\hline & \multicolumn{2}{|c|}{ Richards } & \multicolumn{2}{|c|}{ N 19} & \multicolumn{2}{|c|}{ s 43} \\
\hline Expt no. & $\mathbf{1}$ & 2 & $\mathbf{1}$ & 2 & 1 & 2 \\
\hline $\begin{array}{l}\mathrm{H}_{2} \mathrm{O}_{2}+\text { cocci } \\
\mathrm{H}_{2} \mathrm{O}_{2}+\text { glucose }+ \text { cocci } \\
{ }^{\mathrm{H}_{2}} \mathrm{O}_{2}+\text { glucose }+ \text { cocci }\end{array}$ & $\begin{array}{l}0 \cdot 14 \\
0 \cdot 80 \\
0 \cdot 035\end{array}$ & $\begin{array}{l}0 \cdot 11 \\
1 \cdot 36 \\
0 \cdot 07\end{array}$ & $\begin{array}{l}0 \cdot 11 \\
0 \cdot 12 \\
0 \cdot 035\end{array}$ & $\begin{array}{l}0 \cdot 068 \\
0 \cdot 35 \\
0 \cdot 035\end{array}$ & $\begin{array}{l}0 \cdot 39 \\
0 \cdot 39 \\
0 \cdot 027\end{array}$ & $\begin{array}{l}0 \cdot 12 \\
0 \cdot 45 \\
0 \cdot 048\end{array}$ \\
\hline
\end{tabular}

* Acidified before adding suspension of cocci.

The annullment of the inhibitory effect on Streptococcus pyogenes by glutathione and thioglycollic acid suggested that sulphydryl enzymes were involved and led to a determination of the effect of the components of the inhibitory complex on glyceraldehyde-phosphate dehydrogenase and lactic dehydrogenase activity. An active triosephosphate dehydrogenase was found in cell-free extracts of three different serotypes of $S$. pyogenes. Each of the enzymes required cysteine for activity. Each was affected in the same manner by hydrogen peroxide, lactoperoxidase and thiocyanate when these substances were tested singly or in combination. The enzyme was incubated for $30 \mathrm{~min}$. at $25^{\circ}$ with the components of the inhibitory complex before adding glyceraldehyde-3-phosphate to start the reaction. Tested singly neither substance had any inhibitory effect on triosephosphate oxidation. The rate of oxidation was always equal to or exceeded that in the control when lactoperoxidase, thiocyanate, or their combination was tested and slightly less than the control when hydrogen peroxide alone was tested (Fig. 4).

Complete inhibition of triosephosphate oxidation resulted when hydrogen peroxide and lactoperoxidase were present. Addition of $0.0036 \mathrm{~m}$-cysteine completely annulled the inhibition, whereas $0.009 \mathrm{M}$-glutathione also annulled the inhibition but not as effectively (Fig. 5). The mixture of lactoperoxidase, thiocyanate and hydrogen peroxide inhibited the reaction $10-25 \%$. Hydrogen peroxide and thiocyanate, without lactoperoxidase, caused erratic changes in extinction values immediately upon addition of the substrate, followed by a slower rate of substrate oxidation, which after $10 \mathrm{~min}$. was equal to that of the samples in which only hydrogen peroxide was present.

Purified triosephosphate dehydrogenase from rabbit muscle was inhibited about 
$85 \%$ with one-tenth the concentration of hydrogen peroxide $(0.000167 \mathrm{M})$ used in the reactions with the crude enzyme from Streptococcus pyogenes. The inhibition was completely annulled with $0.0027 \mathrm{M}$-glutathione.

Purified lactic dehydrogenase was inhibited by hydrogen peroxide $(0.000167 \mathrm{M})$ but was not reactivated by glutathione. However, when the enzyme was incubated with the peroxide in the presence of $0.00267 \mathrm{M}$-glutathione, the enzyme was protected from inactivation.

The difference in response of the Lancefield Group A and B streptococci to the inhibitory complex indicated differences in their pathways of energy metabolism. To test this idea, the rate of glucose oxidation by suspensions of three strains of

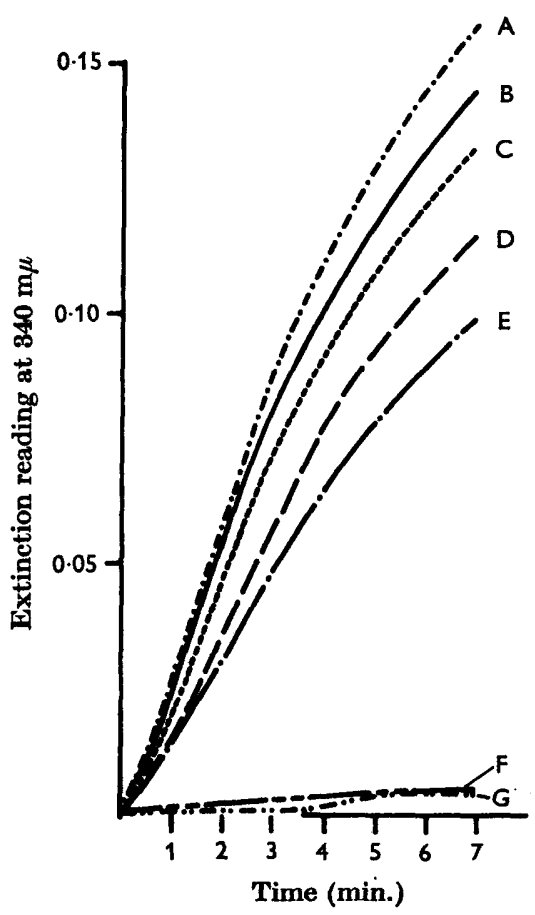

Fig. 4

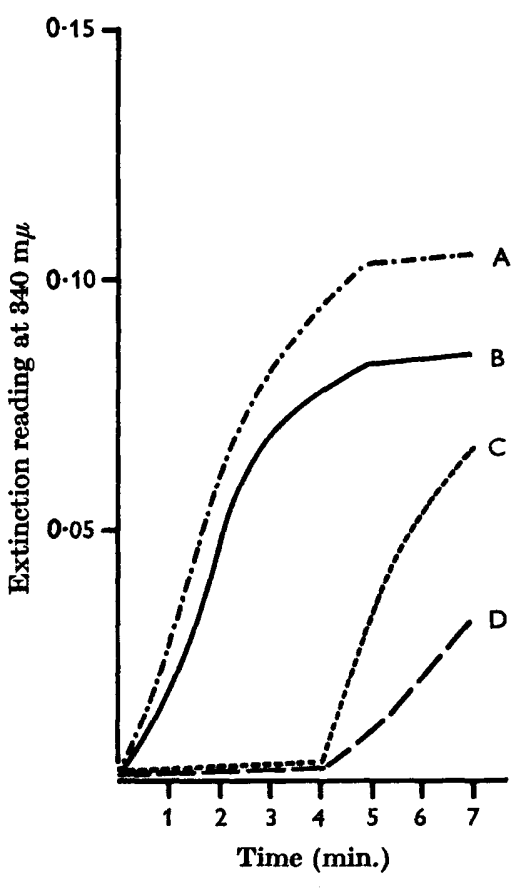

Fig. 5

Fig. 4. Effect of lactoperoxidase, hydrogen peroxide, thiocyanate, and their mixture on glyceraldehyde-8-phosphate dehydrogenase in extracts of Streptococcus pyogenes. Volume $8 \mathrm{ml}$. Reactants; $0.03 \mathrm{~m}-\mathrm{Na}_{4} \mathrm{P}_{2} \mathrm{O}_{7}$ (pH 8.4); $0.05 \mathrm{M}-\mathrm{Na}_{2} \mathrm{HAsO}_{4}$ (pH 8.4); DPN (6 mg./ml.) 0.10 ml.; 0.004 M-DL cysteine (pH 8.4); $0.006 \mathrm{M}$-glyceraldehyde-3-phosphate (Na); $1.66 \times 10^{-6}$ m-hydrogen peroxide; ammonium thiocyanate, $8.3 \mu \mathrm{g} . / \mathrm{ml}$.; lactoperoxidase, 0.6 units $/ \mathrm{ml}$.; bacterial extract, $0.25 \mathrm{ml}$. containing $8.25 \mathrm{mg}$. protein $/ \mathrm{ml} . \mathbf{A}=$ lactoperoxidase; $\mathbf{B}=$ ammonium thiocyanate; $\mathbf{C}=$ control; $\mathbf{D}=$ hydrogen peroxide; $\mathbf{E}=$ lactoperoxidase, thiocyanate, + hydrogen peroxide; $\mathbf{F}=$ lactoperoxidase + hydrogen peroxide; $\mathbf{G}=$ control minus cysteine.

Fig. 5. Inhibition of glyceraldehyde-3-phosphate dehydrogenase in extracts of Streptococcus pyogenes and reversal of the inhibition with cysteine and glutathione. Concentration of reactants same as in Fig. 4. Bacterial extract contained $5 \mathrm{mg}$. protein/ml. Reactivation by addition of $0.8 \mathrm{ml}$. $0.04 \mathrm{M}$-cysteine or $0.3 \mathrm{ml}$. $0.1 \mathrm{M}$-glutathione. Curve $A=$ control; curve $B=$ hydrogen peroxide; curve $\mathbf{C}=$ hydrogen peroxide +lactoperoxidase with $0.3 \mathrm{ml}$. $0.04 \mathrm{M}$-cysteine added 8 min. after starting reaction; curve $D=$ same as C but with $0 \cdot 8 \mathrm{ml}$. 0.1 M-glutathione added. 
Streptococcus pyogenes and six strains of $S$. agalactiae grown in stationary and shaker cultures was determined (Table 3 ). The $\mathbf{Q}_{\mathbf{o}_{2}}$ values with cocci grown in stationary cultures for all cultures were low. However, the $S$. agalactiae respiration showed a sensitivity to $0.001 \mathrm{M}-\mathrm{KCN}$ which was not evident with $S$. pyogenes.

Table 3. Glucose oxidation by suspensions of Streptococcus agalactiae and Streptococcus pyogenes grown in stationary and shaken cultures

\begin{tabular}{|c|c|c|c|c|}
\hline \multirow[b]{2}{*}{ Culture } & \multicolumn{2}{|c|}{ Stationary culture } & \multicolumn{2}{|c|}{ Shaken culture } \\
\hline & $\mathbf{Q}_{\mathbf{O}_{8}}$ & $\begin{array}{l}\text { hibition } \\
\text { M-KCN) }\end{array}$ & $\mathbf{Q}_{\mathbf{O}_{2}}$ & $\begin{array}{c}\% \text { inhibition } \\
(0.001 \mathrm{M}-\mathrm{KCN})\end{array}$ \\
\hline $\begin{array}{l}\text { S. agalactiae } \\
660-1 \\
80\end{array}$ & $\begin{array}{l}1 \cdot 7 \\
4 \cdot 2\end{array}$ & $\begin{array}{l}29 \\
53\end{array}$ & $\overline{1 \cdot 1}$ & $\begin{array}{c}\text { None } \\
\mathbf{3 3}\end{array}$ \\
\hline $\begin{array}{l}\text { Cornell } 48 \\
142 \\
356 \\
\mathbf{3 8 3} \\
50\end{array}$ & $\begin{array}{l}3 \cdot 8 \\
0 \\
4 \cdot 0 \\
0 \cdot 19 \\
2 \cdot 3\end{array}$ & $\begin{array}{r}38 \\
0 \\
62 \\
60 \\
29\end{array}$ & $\begin{array}{r}5 \cdot 3 \\
20 \cdot 0 \\
50 \cdot 0 \\
101 \cdot 0 \\
124 \cdot 0\end{array}$ & $\begin{array}{l}24 \\
45 \\
83 \\
84 \\
83\end{array}$ \\
\hline $\begin{array}{l}\text { S. pyogenes } \\
\qquad \begin{array}{l}\text { Richards } \\
\text { N } 19 \\
\text { s } 43\end{array}\end{array}$ & $\begin{array}{l}8 \cdot 0 \\
8 \cdot 0(6 \cdot 5) \\
4 \cdot 3\end{array}$ & $\begin{array}{l}\text { None } \\
\text { None } \\
\text { None }\end{array}$ & $\begin{array}{r}6 \cdot 6 \\
10 \cdot 0 \\
10 \cdot 0\end{array}$ & $\begin{array}{c}\text { None } \\
\text { None } \\
-\end{array}$ \\
\hline
\end{tabular}

Certain strains of Streptococcus agalactiae grown on the shaker developed the capacity of using oxygen as a hydrogen acceptor, whereas others either were not altered or were adversely affected by aeration. The strains which developed strong oxidative mechanisms for glucose, i.e. strains 50, 356, 383, also had their respiration inhibited more than $80 \%$ by $0.001 \mathrm{M}-\mathrm{KCN}$. The strains which did not develop a strong glucose oxidizing system when grown with aeration were less affected by cyanide. $S$. pyogenes respiration was not affected by growth in shaker cultures. Endogenous respiration with all cultures was low, $1-5 \mu 1 . / \mathrm{O}_{2} / \mathrm{mg}$. dry-wt. cocci/6 hr.

The dependence of Streptococcus pyogenes and only partial dependence of certain strains of $S$. agalactiae on a fermentative pathway for energy is supported by other evidence. Suspensions of aerobically or anaerobically grown $S$. pyogenes converted glucose quantitatively to lactic acid. They had the same percentage of their total flavins as flavinadeninedinucleotide and their slow respiration was unaffected by 0.001 m-cyanide.

Suspensions of Streptococcus agalactiae grown aerobically had about 5 times more of their total flavin as the metabolically active flavinadeninedinucleotide than anaerobically grown cocci. As much as $85 \%$ of their respiration was inhibited by 0.001 $\mathrm{M}$-cyanide and in the absence of cyanide as much as one-third of the glucose utilized was not accounted for as lactic acid. Anaerobically grown cocci converted glucose quantitatively to lactic acid and aerobically grown cocci were diverted toward a fermentative pathway when their respiration was blocked with cyanide. The behaviour of the less aerobic strain 142 was not so strongly affected by growth conditions or the cyanide (Tables 4 and 5 ). 
Table 4. Lactic acid yield from glucose used by suspensions of Streptococcus agalactiae in the presence and absence of 0.001M-cyanide

Reactions run aerobically in respirometer flasks

\begin{tabular}{|c|c|c|c|c|}
\hline \multirow{2}{*}{$\begin{array}{c}\text { Growth } \\
\text { conditions } \\
\text { S. agalactiae }\end{array}$} & \multicolumn{2}{|c|}{ Anaerobic } & \multicolumn{2}{|c|}{ Aerobic } \\
\hline & - & $\begin{array}{r}+\mathbf{K C N} \\
\text { Lact }\end{array}$ & \%* & $+\mathbf{K C N}$ \\
\hline 50 & $85 \cdot 0$ & $89 \cdot 0$ & $62 \cdot 8$ & $79 \cdot 0$ \\
\hline 383 & 92.5 & $98 \cdot 5$ & $67 \cdot 0$ & $85 \cdot 0$ \\
\hline 356 & $105 \cdot 0$ & $105 \cdot 0$ & $72 \cdot 0$ & $88 \cdot 2$ \\
\hline 142 & $83 \cdot 0$ & $104 \cdot 0$ & $86 \cdot 0$ & $92 \cdot 5$ \\
\hline
\end{tabular}

Table 5. Flavinadeninedinucleotide content as percentage of total flavins in aerobically and anaerobically grozen Streptococcus agalactiae and Streptococcus pyogenes

$\begin{array}{ccc} & \begin{array}{c}\text { Total } \\ \text { flavin } \\ \text { as } \\ \text { FAD }\end{array} & \begin{array}{c}\% \text { total } \\ \text { flavin }\end{array} \\ \text { riboflavin } & \text { as FAD }\end{array}$

S. agalactiae $\mathbf{5 0}$

Anaerobic Aerobic

S. pyogenes s 43

\begin{tabular}{|c|c|}
\hline $26 \cdot 4$ & $267 \cdot 6$ \\
\hline $113 \cdot 0$ & $223 \cdot 3$ \\
\hline
\end{tabular}

$\begin{array}{llcc}\text { Anaerobic } & 54 & 95 & \mathbf{2 7 \cdot 2} \\ \text { Aerobic } & 94 \cdot 3 & 161 \cdot 2 & \mathbf{2 7 \cdot 9}\end{array}$

\section{DISCUSSION}

The data presented confirm the work of Reiter et al. (1963) who found that thiocyanate was necessary for growth inhibition of lactoperoxidase-sensitive streptococci. It is also necessary for the inhibition of Streptococcus pyogenes in the chemically defined culture medium. Neither lactoperoxidase or thiocyanate alone had any effect. That hydrogen peroxide is also necessary was demonstrated by a lack of inhibition when catalase or reducing agents were present. Reiter et al. (1964) found that inhibition of $S$. pyogenes (Pope) occurred in a semi-defined medium but not in heated milk to which lactoperoxidase was added. However, lactoperoxidase and thiocyanate inhibited the growth of $S$. cremoris $\mathbf{9 7 2}$ in a defined medium.

Annulment of the inhibitory effect for Streptococcus pyogenes with reducing agents confirms the results of others (Wilson \& Rosemblum, 1952; Auclair, 1954) obtained in complex growth media. It suggests also that inhibition with lactoperoxidase and thiocyanate is the result of an oxidative change in which sulphydryl groups of enzymes are inactivated and then restored to activity by addition of a reducing agent.

Streptococcus agalactiae strains responded to the inhibitory complex in the chemically defined medium by a maximum lag of $6 \mathrm{hr}$ in growth initiation. This 
agrees with earlier work done in milk where $S$. pyogenes was found to die, whereas, $S$. agalactiae began to grow rapidly (Jones \& Simms, 1930), after an extended lag period. $S$. agalactiae strains adapt to use oxygen as an electron acceptor to various degrees when grown on a shaker. Those strains which develop the strongest oxidative tendencies are least affected by the inhibitory complex. Strains 50, 356 and 383 developed the strongest oxygen uptake with glucose as a substrate and their respiration was $80-85 \%$ inhibited by cyanide. This result implies that iron-containing enzymes are used in their respiration and they perhaps have a good hydrogen peroxide tolerance. The peroxidase-like mechanism identical to that described for $S$. faecalis as a respiratory pathway is excluded, because it was not sensitive to cyanide (Seeley \& Vandemark, 1951). The fact that $S$. agalactiae was not compeletely tolerant to peroxide was indicated by a more rapid rate of growth when catalase was added to the chemically defined medium and by a more rapid rate of respiration when catalase was added to coccal suspensions. Dr R. W. Brown of our laboratory (personal communication) has noted that the inhibition of growth of $S$. agalactiae by raw milk is overcome completely by catalase. The presence of hydrogen peroxide is necessary for the inhibitory system to function against $S$. pyogenes as it is for $S$. cremoris (Jago \& Morrison, 1962). S. pyogenes cultures used in this work did not have their oxidative abilities enhanced by growth under aerated conditions nor was their slow rate of respiration affected by cyanide. Even in the presence of oxygen they are obliged to obtain their energy by the fermentative pathway.

The cultures of Streptococcus agalactiae and $S$. pyogenes which were studied here were able to respire slowly in the presence of $5 \mu$ mole hydrogen peroxide $/ \mathrm{ml}$. and to cause disappearance of the peroxide. Whether the hydrogen peroxide decomposition was non-enzymic and caused by its reaction with pyruvic acid resulting from glucose fermentation, or to peroxidase activity is uncertain (Greisen \& Gunsalus, 1944). There exists in both organisms, therefore, a mechanism for destroying or utilizing hydrogen peroxide and preventing its accumulation. In addition to the catalase effect observed with $S$. pyogenes $\mathbf{4} 43$ (Table 2, Expt. 1), a similar observation was made with $S$. pyogenes Richards. The catalase activity, however, was not reproducible from one batch of cocci to the next as was the peroxidase activity. Inability to decompose hydrogen peroxide is not a suitable explanation for the sensitivity of $\boldsymbol{S}$. pyogenes cultures to lactoperoxidase and thiocyanate.

The most striking metabolic difference found between Streptococcus agalactiae and $S$. pyogenes was the development under aerobic growth conditions of a cyanidesensitive respiratory system in certain strains of $S$. agalactiae. Thus, they have an alternative oxidative pathway for obtaining energy from glucose which was not sensitive to lactoperoxidase and thiocyanate. Even though suspensions of some $S$. agalactiae strains did not develop increased respiratory activity when they were grown in shaken cultures, they did adapt after a delay to rapid growth in the defined medium in the presence of the inhibitor components. These cultures must also, though more slowly, develop an alternative pathway for their energy supply. The nature of the cyanide-sensitive respiration is under study.

Comparative studies of the effect of the components of the inhibitory complex (lactoperoxidase + thiocyanate + hydrogen peroxide) on glyceraldehydephosphate dehydrogenase activity and the growth of Streptococcus pyogenes suggest that this enzyme may be a site of inhibitor action. The inhibition of both appears to be an 
oxidative reaction and annulment of the inhibition results from adding reducing agents such as glutathione or cysteine. The annulment of growth inhibition of $\boldsymbol{S}$. pyogenes with glutathione, thioglycollic acid and catalase suggests that a sulphydryl enzyme is involved and that the inhibition is due to an oxidative change in which the -SH groups are converted to disulphide. Krimsky \& Racker (1952) identified glutathione as the prosthetic group of glyceraldehyde-3-phosphate dehydrogenase from rat liver. If glyceraldehydrophosphate dehydrogenase is active only in the sulphydryl form, it is reasonable to believe that inactivation occurs through conversion of HS- to -S-S- which is restored to the active sulphydryl enzyme by glutathione. A very important function of glutathione might be to keep HS-enzymes, active only in the sulphydryl form, in the reduced form (Dixon \& Webb, 1958). The lack of inhibition of the crude glyceraldehyde-3-phosphate dehydrogenase from streptococci by lactoperoxidase + hydrogen peroxide + thiocyanate suggests that the thiocyanate is competing with the oxidizable groups on the dehydrogenase in the bacterial extract.

The role of thiocyanate for inhibition by lactoperoxidase is not clear. Myeloperoxidase, but not horseradish peroxidase, in the presence of hydrogen peroxide oxidizes thiocyanate to sulphate and cyanide. Evidence for an unstable intermediate in the thiocyanate was obtained by measuring absorption at $235 \mathrm{~m} \mu$ (Sörbo \& Ljunggren, 1958). Horseradish peroxidase does not substitute for lactoperoxidase in the inhibition of Streptococcus pyogenes in the chemically defined culture medium nor with $S$. cremoris in a supplemented whey ultrafiltrate medium (Jago \& Morrison, 1962). Thiouracil, thiourea and thiocyanate exist in two tautomeric forms, one containing a sulphydryl group and the other containing sulphur linked to carbon through a double bond; however, thiourea and thiouracil did not, under similar test conditions, replace thiocyanate in the growth inhibitor system for $S$. pyogenes.

\section{REFERENCES}

AuclaIr, J. E. (1954). The inhibition of microorganisms by raw milk. III. Distribution and properties of two inhibitory substances, lactenin 1 and lactenin 2. J. Dairy Res. 21, 323.

Auclair, J. E. \& Hrrsch, A. (1953). The inhibition of microorganisms by raw milk. I. The occurrence of inhibitory and stimulatory phenomena. Methods of estimation. $J$. Dairy Res. 20, 45.

Colowick, S. \& Kaplan, N. O. (1959). Methods in Enzymology, vol. I, 401.

DeLuca, C., Weber, M. M. \& Kaplan, N. O. (1956). A specific spectrophotometric assay for flavinadeninedinucleotide. $J$. biol. Chem. 223, 559.

Dixon, M. \& Webb, E. C. (1958). Enzymes, p. 409. New York: Academic Press, Inc.

Greisen, E. C. \& Gunsalus, I. C. (1944). An alcohol oxidation system in a streptococcus which functions without hydrogen peroxide accumulation. $J$. Bact. 48, 515.

JAGo, G. R. \& Morrison, M. (1962). Antistreptococcal activity of lactoperoxidase. III. Proc. Soc. exp. Biol. Med. 111, 585.

JoNes, F. S. \& SImms, H. F. (1930). The bacterial growth inhibitor (lactenin) of milk. I. The preparation in concentrated form. J. exp. Med. 51, 32\%.

KRIMSKX, I. \& RACKER, E. (1952). Glutathione: a prosthetic group of triosephosphate dehydrogenase. J. biol. Chem. 198, 721.

Mickelson, M. N. (1964). Chemically defined medium for growth of Streptococcus pyogenes. J. Bact. 88, 158.

Morrison, M. \& Hulteurst, D. E. (1963). Lactoperoxidase. II. Isolation. J. biol. Chem. 238, 2847. 
Portmann, A. \& Auclatr, J. E. (1959). Relation entre la lactenin $\mathrm{L}_{2}$ et la lactoperoxydase . Le Lait, 39, 147.

Reiter, B., Pickering, A. \& Oram, J. D. (1964). An inhibitory system: lactoperoxidase/ thiocyanate/hydrogen peroxide in raw milk. 4th int. Symp. Food Microbiology, p. 297. SIK, Goteberg, Sweden.

Reiter, B., Pickering, A., Oram, J. D. \& Pope, G. S. (1963). Peroxide, thiocyanate inhibition of streptococci in raw milk. J. gen. Microbiol. 33, xii.

SeEley, H. W. \& VANDemark, P. J. (1951). An adaptive peroxidation by $S$. faecalis. J. Bact. 61, 27.

Sörbo, H. \& LJUNGGren, J. G. (1958). The catalytic effect of peroxidase on the reaction of hydrogen peroxide and certain sulfur compounds. Acta chem. scand. 12, 470.

Stadtiman, E. R., Novelin, G. D. \& Lipmann, F. (1951). Coenzyme A function in acetyl transfer by a phosphotransacetylase system. J. biol. Chem. 191, 365.

Umbreit, W. W., Burris, R. H. \& StaufFer, J. F. (1957). Manometric techniques, 2nd ed. Minneapolis, Minn.: Burgess Publishing Co.

Wrlson, A. T. \& Rosenblum, H. (1952). The antistreptococcal property of milk. I. Some characteristics of the activity of lactenin in vitro. The effect of lactenin on hemolytic streptococci of several serological groups. J. exp. Med. 95, 25.

Wirson, A. T. \& Rosenblum, H. (1952). The antistreptococcal property of milk. II. The effects of anaerobiosis, reducing agents, thiamine and other chemicals on lactenin action. J. exp. Med. 95, 39.

Wright, R. C. \& Tramer, J. (1958). Factors affecting the activity of cheese starters. The role of milk peroxidase. J. Dairy Res. 25, 104.

Addendum. Suspensions of three strains of Streptococcus agalactiae, 660-1, 80, and Cornell 48 oxidized glucose with $\mathrm{Q}_{\mathrm{a}}$ values of 55,26 and 22 respectively, if the cocci were harvested when $30-50 \%$ of the glucose in the growth medium had been used (6-10 hr incubation). Eighty to eighty-five $\%$ of this respiration was inhibited by 0.001 M-cyanide. 